\title{
Microbial life at high salt concentrations: phylogenetic and metabolic diversity
} Aharon Oren

\begin{abstract}
Address: Department of Plant and Environmental Sciences, The Institute of Life Sciences, and the Moshe Shilo Minerva Center for Marine
\end{abstract} Biogeochemistry, The Hebrew University of Jerusalem, Jerusalem 91904, Israel

Email: Aharon Oren - orena@cc.huji.ac.il

Published: 15 April 2008

Saline Systems 2008, 4:2 doi:10.1186/1746-1448-4-2

This article is available from: http://www.salinesystems.org/content/4/I/2

(c) 2008 Oren; licensee BioMed Central Ltd.

This is an Open Access article distributed under the terms of the Creative Commons Attribution License (http://creativecommons.org/licenses/by/2.0), which permits unrestricted use, distribution, and reproduction in any medium, provided the original work is properly cited.
Received: 12 November 2007

Accepted: 15 April 2008

\begin{abstract}
Halophiles are found in all three domains of life. Within the Bacteria we know halophiles within the phyla Cyanobacteria, Proteobacteria, Firmicutes, Actinobacteria, Spirochaetes, and Bacteroidetes. Within the Archaea the most salt-requiring microorganisms are found in the class Halobacteria. Halobacterium and most of its relatives require over $100-150 \mathrm{~g} / \mathrm{l}$ salt for growth and structural stability. Also within the order Methanococci we encounter halophilic species. Halophiles and nonhalophilic relatives are often found together in the phylogenetic tree, and many genera, families and orders have representatives with greatly different salt requirement and tolerance. A few phylogenetically coherent groups consist of halophiles only: the order Halobacteriales, family Halobacteriaceae (Euryarchaeota) and the anaerobic fermentative bacteria of the order Halanaerobiales (Firmicutes). The family Halomonadaceae (Gammaproteobacteria) almost exclusively contains halophiles. Halophilic microorganisms use two strategies to balance their cytoplasm osmotically with their medium. The first involves accumulation of molar concentrations of $\mathrm{KCl}$. This strategy requires adaptation of the intracellular enzymatic machinery, as proteins should maintain their proper conformation and activity at near-saturating salt concentrations. The proteome of such organisms is highly acidic, and most proteins denature when suspended in low salt. Such microorganisms generally cannot survive in low salt media. The second strategy is to exclude salt from the cytoplasm and to synthesize and/or accumulate organic 'compatible' solutes that do not interfere with enzymatic activity. Few adaptations of the cells' proteome are needed, and organisms using the 'organic-solutes-in strategy' often adapt to a surprisingly broad salt concentration range. Most halophilic Bacteria, but also the halophilic methanogenic Archaea use such organic solutes. A variety of such solutes are known, including glycine betaine, ectoine and other amino acid derivatives, sugars and sugar alcohols. The 'high-salt-in strategy' is not limited to the Halobacteriaceae. The Halanaerobiales (Firmicutes) also accumulate salt rather than organic solutes. A third, phylogenetically unrelated organism accumulates $\mathrm{KCl}$ : the red extremely halophilic Salinibacter (Bacteroidetes), recently isolated from saltern crystallizer brines. Analysis of its genome showed many points of resemblance with the Halobacteriaceae, probably resulting from extensive horizontal gene transfer. The case of Salinibacter shows that more unusual types of halophiles may be waiting to be discovered.
\end{abstract}




\section{Introduction}

At the symposium on 'General \& Applied Aspects of Halophilic Microorganisms', held in Alicante, Spain in September 1989, Hans Trüper presented a lecture entitled: "Halophily, taxonomy, phylogeny and nomenclature". The talk summarized different aspects of the taxonomy of halophilic microorganisms, the phylogenetic position of the different types of halophiles within the microbial world, and the physiology of the diverse groups of extreme and moderate halophiles. An attempt was made to detect consistent patterns and correlations between the phylogeny of halophilic microorganisms and the ways they cope with the high salt concentrations in the environment in which they live. A summary of this talk was published three years later in the proceedings volume of the Alicante meeting [1], and there Prof. Trüper and his coworkers presented a critical analysis of the data. They noted a few regular patterns that link the physiological properties of the halophilic organisms with their phylogenetic position. Four such general observations were presented:

(1) "All eubacteria that gain energy from photosynthesis or oxygen-respiration and are capable of haloadaptation, are able to accumulate and/or produce compatible solutes."

(2) "Archaeobacteria and anaerobic fermenting eubacteria are incapable of synthesizing organic compatible solutes."

(3) "Most eubacteria that can grow in non-complex media are capable of ectoine biosynthesis."

(4) "Extreme halophily in non-fermenting eubacteria is usually accompanied by glycine betaine biosynthesis. The complete de novo synthesis of betaine from carbon dioxide or simple organic carbon compounds has only been proven for cyanobacteria, Ectothiorhodospira species and Actinopolyspora halophila."

In the eighteen years that have passed since the Alicante meeting our understanding of the salt-loving microbial world has greatly increased. A large number of new halophilic organisms have been discovered and described, including organisms phylogenetically unaffiliated to previously known halophilic or halotolerant microorganisms. We have also obtained a deeper insight into the physiological mechanisms used by different types of halophiles to adapt to life in hypersaline environments.

Based on the key words in the title of Prof. Trüper's talk "halophily", "taxonomy", "phylogeny" and "nomenclature", this paper first presents an overview of the novel information, followed by a reevaluation of the four above-cited general observations made in 1989 .

\section{Halophily and the phylogenetic tree of life}

Salt dependence and salt tolerance are phenotypic characteristics generally included in the 'polyphasic' characterization of newly discovered microorganisms toward their description as new taxa with new names and the determination of their position within the microbial taxonomy. There is no sharp definition of the term 'halophilic' - 'saltloving'. Some use the term for all organisms that require some level of salt for growth, including concentrations around $35 \mathrm{~g} / \mathrm{l}$ as found in seawater. This is also reflected in prokaryote nomenclature: there are quite a few bacteria with the specific epithet 'halophilus' $(-a,-u m)$ that are of marine origin and do not tolerate salt concentrations much above those of seawater. Examples are Aestuariibacter halophilus, Algoriphagus halophilus (Hongiella halophila), Arcobacter halophilus, Microbacterium halophilum, and Terribacillus halophilus. The use of the specific epithet halophilus to describe marine microorganisms should be discouraged, and it is recommended to reserve this name for true halophiles adapted to life in hypersaline conditions.

A survey of the salt relationships - the minimum salt concentration required for growth, the salinity optimum, and the upper salt limit tolerated - within the microbial world shows a continuum of properties, which makes it nearly impossible to define by sharp boundaries what a halophile is. Moreover, the minimum, optimum and maximum salt concentrations often depend on the medium composition and growth temperature. The most widely used definitions were formulated thirty years ago by Donn Kushner [2] who distinguished different categories: extreme halophiles (growing best in media containing 2.5-5.2 M salt), borderline extreme halophiles (growing best is media containing 1.5-4.0 M salt), moderate halophiles (growing best in media containing $0.5-2.5 \mathrm{M}$ salt), and halotolerant microorganisms that do not show an absolute requirement for salt for growth but grow well up to often very high salt concentrations (considered extremely halotolerant if the growth range extends above $2.5 \mathrm{M}$ salt). These and similar definitions have proved valuable in the classification of microorganisms according to their relationship to salt [3-5]. For the discussions below a simpler operative definition of what a halophile is will suffice: microorganisms that grow optimally at salt concentrations of $50 \mathrm{~g} / \mathrm{l}$ (equivalent to $0.85 \mathrm{M} \mathrm{NaCl}$ ) or higher, and tolerate $100 \mathrm{~g} / \mathrm{l}$ salt (equivalent to $1.7 \mathrm{M}$ $\mathrm{NaCl}$ ) at least.

When examining the distribution of halophiles, as based on the above definition, within the small subunit rRNA sequence-based phylogenetic tree of life, it is clear that halophiles are found in all three kingdoms: Archaea, Bacteria, and Eukarya (Fig. 1) $[3,4,6]$. The figure indicates which groups of microorganisms contain halophilic rep- 


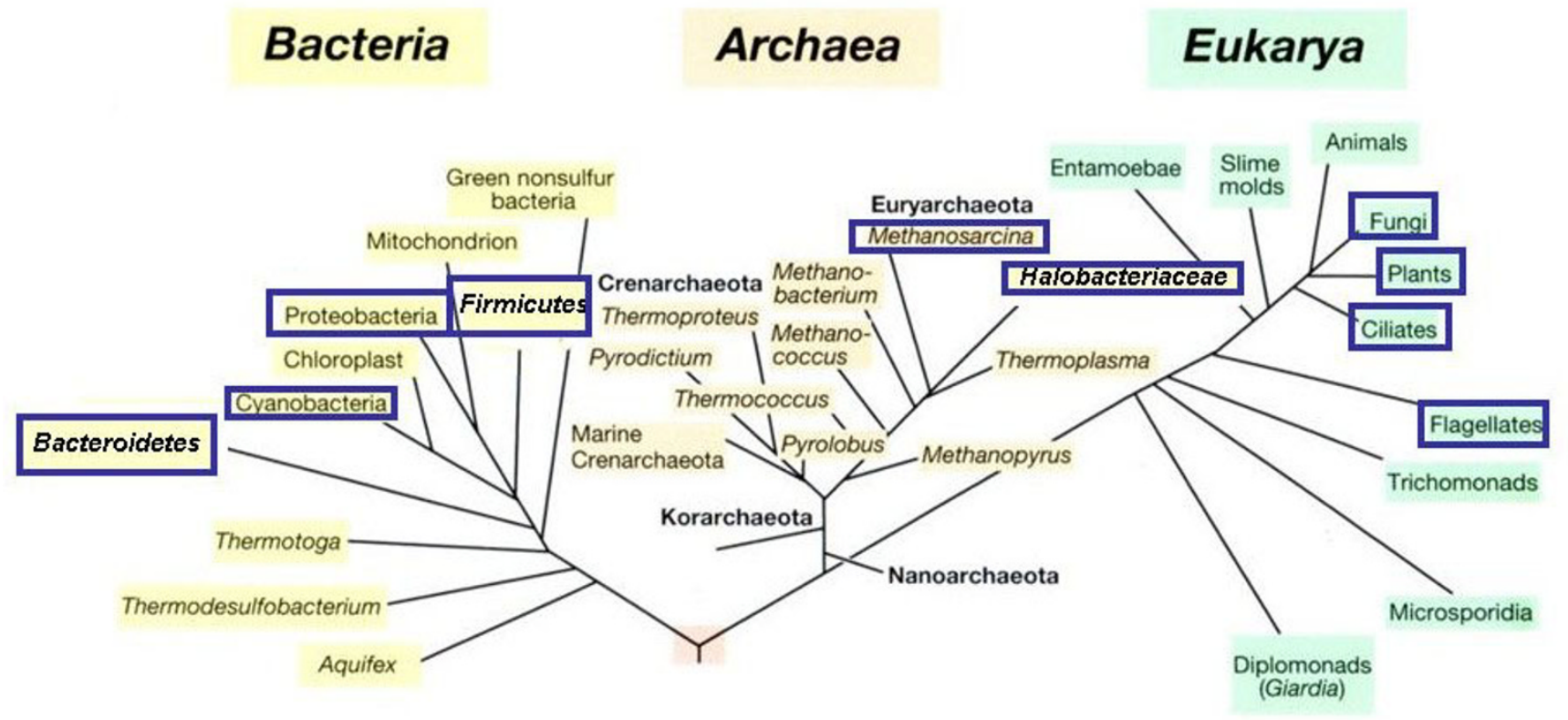

Figure I

The universal phylogenetic tree of life as based on small subunit rRNA gene sequences, and the distribution of halophilic microorganisms within the tree. Groups marked with blue boxes contain at least one halophilic representative (e.g the Bacteroidetes, of which Salinibacter ruber is the sole halophilic member described to date); others such as the Halobacteriales consist entirely of halophiles. The tree is based on Fig. II.I6 in Madigan and Martinko, 2006 (78).

resentatives. Groups marked as such do not necessarily consist solely of halophiles. The opposite is true: there are only a few phylogenetically consistent groups that are composed entirely of halophiles (see below). In most cases halophiles and non-halophilic relatives are found together in the phylogenetic tree, and many genera, families and orders have representatives with greatly different salt requirement and tolerance. Within the Archaea we find the most salt-requiring microorganisms in the order Halobacteriales, which contains a single family, the Halobacteriaceae. Halobacterium and most of its relatives require over 100-150 g/l salt for growth and structural stability. Also within the class Methanothermea (Methanococci), order Methanosarcinales we encounter halophilic or highly halotolerant representatives (genera Methanohalophilus, Methanohalobium). All these belong to the phylum Euryarchaeota; no halophilic representatives have yet been identified within the Crenarchaeota. Halophily is widespread in the bacterial kingdom: we know halophiles within the phyla Cyanobacteria, Proteobacteria, Firmicutes, Actinobacteria, Spirochaetes, and Bacteroidetes.

With a few notable exceptions, the eukaryotic microorganisms form a sadly neglected group as far as the study of their distribution in high-salt environments and their physiological adaptation to life at high salt concentrations is concerned. The unicellular green algae of the genus Dunaliella have been investigated in-depth, as they are the main or sole primary producers in many hypersaline environments, they have become a popular model system for the study of salt adaptation by using organic osmotic 'compatible' solutes, and they have also found biotechnological applications [7]. The occurrence of the brine shrimp (Artemia salina, Artemia franciscana) in salt lakes is also well known, but the discussion of its biology is outside the scope of this review. The Fungi, long neglected in halophile research, contain a number of representatives that by all criteria are true halophiles, both by their absolute requirement for high salt and by their ability to grow up to salt concentrations approaching saturation. Examples are the meristematic fungus Trimmatostroma salinum [8] and the black yeast Hortaea werneckii [9], organisms indigenous to saltern brines and other hypersaline environments. Even more severely neglected is the study of flagellate, ciliate and amoeboid protozoa that live in highsalt environments. The existence of such organisms has been documented already long ago [[10,11]; for an overview of the early literature see [12]), but only recently has the study of truly halophilic heterotrophic nanoflagellates taken off. Different types of halophilic flagellates were found in Korean saltern ponds [13], and two species have thus far been characterized in-depth. The first is Pleurosto- 
mum flabellatum, an organism known already since the 1930s. An isolate from a saltern pond with $313 \mathrm{~g} / \mathrm{l}$ salt has its optimum at $300 \mathrm{~g} / \mathrm{l}$ salt and does not grow below 150-200 g/l [14]. Another bacteriovorous heterotrophic nanoflagellate isolated from a $300 \mathrm{~g} / \mathrm{l}$ saltern pond is Halocafetaria seosinensis, which grows optimally at $150 \mathrm{~g} / \mathrm{l}$ salt, does not grow below $75 \mathrm{~g} / \mathrm{l}$, and tolerates concentrations above $350 \mathrm{~g} / \mathrm{l}$ total dissolved salts [15].

\section{The Halobacteriales, the Halomonadaceae, and the Halanaerobiales: three phylogenetically coherent groups of halophiles}

Within the small subunit rRNA gene sequence-based tree of life we find three groups of prokaryotes that are both phylogenetically and physiologically coherent and consist entirely or almost entirely of halophiles. Within the Euryarchaeota we encounter the order Halobacteriales with a single family, the Halobacteriaceae [16]. In the bacterial kingdom, the family Halomonadaceae (class Gammaproteobacteria, order Oceanospirillales) predominantly contains halophiles [17]. Members of the Halobacteriaceae and the Halomonadaceae are aerobic heterotrophs, some of which have a limited potential for anaerobic growth. The third phylogenetically coherent group contains the anaerobic fermentative bacteria of the order Halanaerobiales (Firmicutes, families Halanaerobiaceae and Halobacteroidaceae) [18].

Our understanding of the phylogenetic and physiological diversity within the Halobacteriaceae and the Halomonadaceae has greatly increased in the past two decades. Extensive programs aimed at the sampling of salt lakes and other saline and hypersaline environments in different countries have led to the characterization and taxonomic description of many new species, so that the number of species names within these two families has increased exponentially. The 1974 edition of 'Bergey's Manual of Determinative Bacteriology' listed 2 genera and 3 species within the family Halobacteriaceae [19]. The next edition of the handbook, published in 1989 under the new name 'Bergey's Manual of Systematic Bacteriology', already had 6 genera and 11 species [20]. The numbers of genera and species increased to 14 and 34, respectively in the 2001 edition [21], and to date (March 2008) the names of no less than 26 genera and 91 different species of Halobacteriaceae have been validly published under the rules of the International Code of Nomenclature of Prokaryotes (Fig. 2 , upper panel). With descriptions of eight additional new species listed as 'in press' in the International Journal of Systematic and Evolutionary Microbiology (as of March 2, 2008), the current trend is expected to continue at least for some more time.

Most species of Halobacteriaceae are true extreme halophiles according to Kushner's definition [2]. However, analysis of $16 \mathrm{~S}$ rRNA genes amplified from environments with salt concentrations below $100 \mathrm{~g} / \mathrm{l}$ shows that the lower salinity boundary that allows development of archaeal halophiles may be substantially lower than that of Halobacterium salinarum, Haloarcula marismortui, and other well-studied members of the group [22]. Descriptions of isolates phylogenetically affiliated with the Halobacteriaceae but with a relatively low salt requirement also started to appear in the literature. A saline spring in Oklahoma whose waters contain $7-10 \mathrm{~g} / \mathrm{l}$ salt, a concentration far too low to support growth of most members of the Halobacteriaceae, recently yielded a novel species of Haloferax, Haloferax sulfurifontis [23] and two species belonging to new genera:Haladaptatus paucihalophilus (the specific epithet signifying its low salt requirement) [24] and Halosarcina pallida [25]. The lower salinity boundary of these species for growth is 60,47 , and $76 \mathrm{~g} / \mathrm{l}$, respectively, but the optimal salt concentrations and the maximal salinity tolerated by these isolates are within the high ranges normally encountered for members of the family. Halobacterium salinarum and most other species of Halobacteriaceae lyse when the salt concentration is lowered below $100 \mathrm{~g} / \mathrm{l}$. However, some of its relatives have a remarkable ability to withstand exposure to low salt concentrations. Out of 131 isolates of Halobacteriaceae obtained from Spanish saltern ponds, 49 did not lyse in $20 \mathrm{~g} / \mathrm{l}$ salt and 13 even survived exposure to $10 \mathrm{~g} / \mathrm{l}$ salt [26]. It was recently shown that isolates obtained from Japanese salterns and affiliated with the genera Halococcus, Halogeometricum and Haladaptatus may survive periods of 1-9 days in salt solutions of seawater concentration [27]. Haloferax sulfurifontis survived incubation for $24 \mathrm{~h}$ at 10-20 g/l salt and $72 \mathrm{~h}$ in $30 \mathrm{~g} / \mathrm{l}$ salt [23], and Haladaptatus paucihalophilus cells even retained their viability after having been suspended for two weeks in distilled water [24]. The sediments of a British salt marsh yielded several isolates of Halobacteriaceae, many of which closely related to Haladaptatus paucihalophilus, which grow slowly at seawater salinity [28].

It must be realized that there is no well-based species concept for the prokaryotes, and the same is therefore true for the halophilic Archaea. The above-presented statistics of the number of species described are all based on some more or less arbitrary ideas of how to define a species and when to decide whether a new isolate may belong to an already known species or should be described as a novel one. A recent evaluation of a large number of isolates of Halobacteriaceae from saltern ponds in Spain and Algeria using multilocus sequence analysis shows that, although clusters can be defined by concatenation of multiple marker sequences, barriers to exchange between them are leaky. No nonarbitrary way to circumscribe 'species' is therefore likely to emerge for the Halobacteriaceae in the near future [29]. 

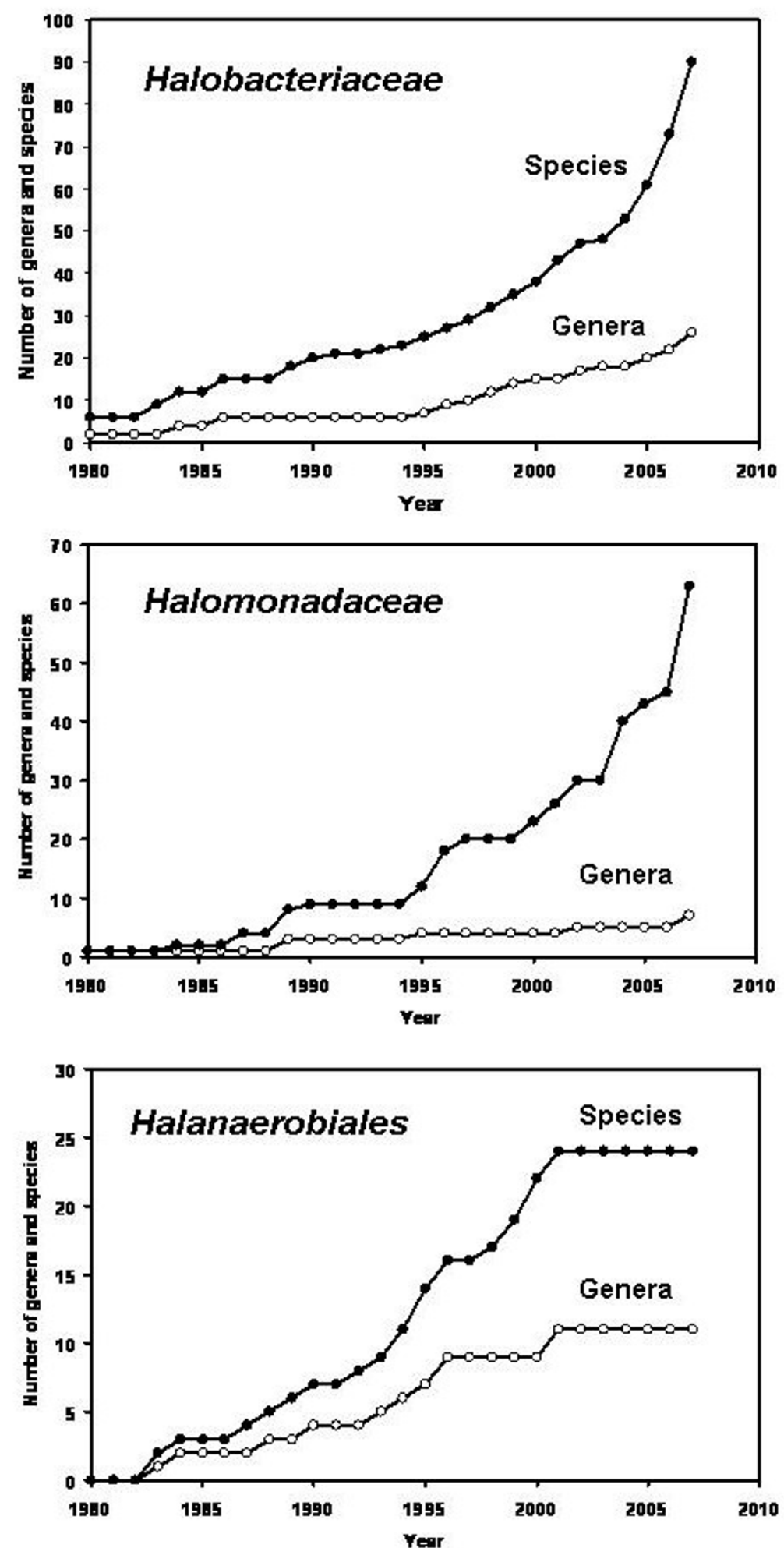

Figure 2

Numbers of different genera and species within the family Halobacteriaceae, the family Halomonadaceae, and the order Halanaerobiales, whose names have been validly published, I 980-2007. 
A dramatic increase in the number of descriptions of new species in recent years can also be observed for the second phylogenetic group that consists (almost) entirely of halophiles: the family Halomonadaceae (Gammaproteobacteria). When Halomonas elongata was isolated in 1980 [30], few people predicted that it would be the first representative of a very large group of metabolically versatile moderate halophiles. The recognition that Halomonas and relatives deserve to be classified in a separate family came in 1988 [31], and the number of species and genera has been rising steadily since ([5,32,33]; Fig. 2, middle panel). Recently two new genera were added to the family, Halotalea and Modicisalibacter [34,35], bringing the census for March 2008 to 7 genera with 63 species whose names have been validly published. Out of these 63 species, 60 can be considered halophiles as based on the above definition. The three genera Zymomonas, Carnimonas, and Cobetia each contain presently one non-halophilic or marine species. As of March 2, 2008, four new species of the genus Halomonas were listed as 'in press' in the International Journal of Systematic and Evolutionary Microbiology.

The third phylogenetically coherent group consisting entirely of halophiles is the interesting but little studied order Halanaerobiales, families Halanaerobiaceae and Halobacteroidaceae (Low G+C branch of the Firmicutes) [18]. This group consists of obligate anaerobes, and most live by fermentation of sugars or (in a few cases only) amino acids. That the study of this group has to some extent been neglected in comparison with the other halophile branches is obvious from the number of new species described: the count for March 2008 was 11 genera and 24 species (Fig. 2, lower panel), the two most recently added genera and species - Halonatronum saccharophilum and Selenihalanaerobacter shriftii having been described in 2001. The latter species is of special interest as it makes a living by anaerobic respiration rather than by fermentation [36]. The family Halanaerobiaceae also contains a thermophilic representative: Halothermothrix orenii, an organism isolated from a hypersaline lake in Tunisia that combines anaerobic life at high salt (optimum $100 \mathrm{~g} / \mathrm{l}$, tolerating up to $200 \mathrm{~g} / \mathrm{l}$ salt) with a high temperature optimum $\left(60^{\circ} \mathrm{C}\right.$, growing up to $\left.68^{\circ} \mathrm{C}\right)[37]$.

\section{Mechanisms of adaptation of halophilic microorganisms to life at high salt}

Trüper's four 'postulates', as presented at the Alicante symposium [1], deal with the presence, distribution and biosynthesis of organic osmotic solutes, and they mention specific compounds such as ectoine and glycine betaine.

A basic property of all halophilic microorganisms is the fact that their cytoplasm has to be at least isoosmotic with their surrounding medium. Biological membranes are permeable to water, and active energy-dependent inward transport of water to compensate for water lost by osmotic processes is energetically not feasible. Moreover, cells that keep a turgor need even to maintain their intracellular osmotic pressure higher than that of their environment $[38,39]$.

There are two fundamentally different strategies used by halophilic microorganisms to balance their cytoplasm osmotically with their medium. The first involves accumulation of molar concentrations of potassium and chloride. This strategy requires extensive adaptation of the intracellular enzymatic machinery to the presence of salt, as the proteins should maintain their proper conformation and activity at near-saturating salt concentrations [40]. The proteome of such organisms is highly acidic, and most proteins denature when suspended in low salt. Such 'high-salt-in strategy' microorganisms generally cannot survive in low salt media.

Although it can be calculated that the 'high-salt-in strategy' is energetically less costly to the cell than the biosynthesis of large amounts of organic osmotic solutes [41], this strategy is not widely used among the different phylogenetic and physiological groups of halophiles (Fig. 3). It is best known from the extremely halophilic Archaea of the family Halobacteriaceae, and species such as Halobacterium salinarum and Haloarcula marismortui have become popular model organisms to examine the implications that the maintenance of high intracellular $\mathrm{KCl}$ concentrations has on the life of a cell. Our understanding of the biology of the Halobacteriaceae has greatly increased in recent years thanks to the elucidation and analysis of the genome sequences of Halobacterium NRC-1 [42,43], Haloarcula marismortui [44], Natronomonas pharaonis [45], and Halquadratum walsbyi [46].

The strategy of salt adaptation is not limited to the aerobic halophilic Archaea. The anaerobic fermentative Halanaerobiales (Bacteria, Firmicutes) also use $\mathrm{KCl}$ rather than organic solutes to osmotically balance their cytoplasm, and they also have adapted their intracellular machinery to tolerate the presence of salt $[18,47]$. The third type of organism, phylogenetically unrelated with the abovementioned two groups, in which the 'high-salt-in-strategy' was recently identified to occur, is the aerobic red extremely halophilic Salinibacter ruber (Bacteroidetes). The properties of this intriguing organism are discussed below in further depth.

Far more widespread in nature is the second strategy of haloadaptation, based on the biosynthesis and/or accumulation of organic osmotic solutes. Cells that use this strategy exclude salt from their cytoplasm as much as possible. The high concentrations of organic 'compatible' sol- 


\section{Bacteria}

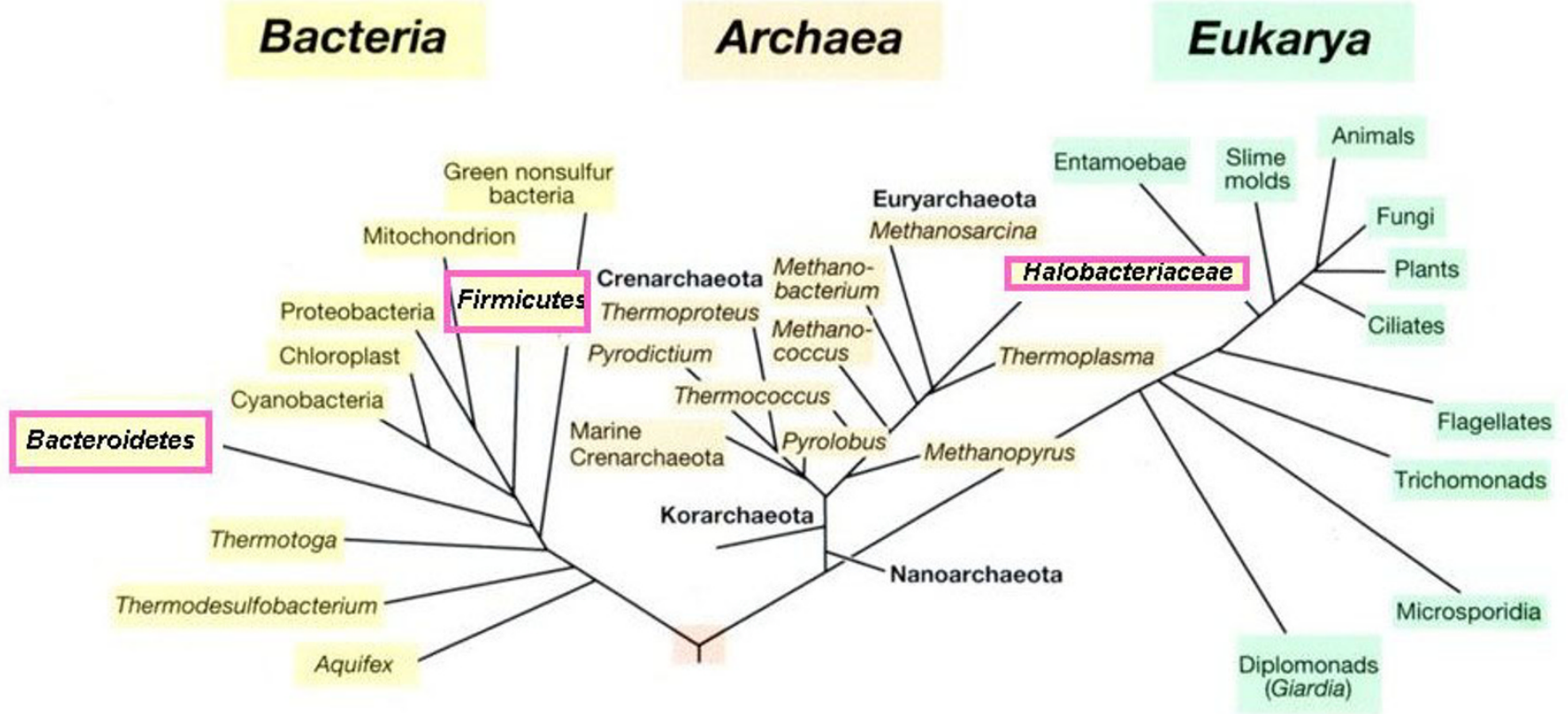

Figure 3

Distribution within the phylogenetic tree of microorganisms accumulating $\mathrm{KCl}$ as their sole or main osmotic solute. Groups marked with purple boxes contain at least one halophilic representative (e.g. Salinibacter ruber within the Bacteroidetes). The group of the Firmicutes contains both microorganisms that use $\mathrm{KCl}$ for osmotic balance (the order Halanaerobiales within the low G+C branch, consisting of anaerobic fermentative organisms) and different halophilic aerobes (Halobacillus spp. and others) that accumulate inorganic solutes. High intracellular $\mathrm{KCl}$ concentrations are also found in the methanogenic halophiles, but these accumulate organic solutes as well.

utes do not greatly interfere with normal enzymatic activity. Few adaptations of the cells' proteome are therefore needed. Such organisms can often adapt to a surprisingly broad salt concentration range [5]. The list of organic compounds that have been shown to serve as osmotic solutes in halophilic microorganisms - prokaryotic as well as eukaryotic - is extensive. Most compatible solutes are based on amino acids and amino acid derivatives, sugars, or sugar alcohols [48-50]. Most are either uncharged or zwitterionic (Fig. 4).

Use of the 'low-salt-in strategy' of haloadaptation with accumulation of organic osmotic solutes is widespread in the small subunit rRNA sequence-based phylogenetic tree of life (Fig. 5). Not all groups of halophiles have yet been examined for the occurrence and distribution of organic solutes. For example, no information is available on the composition and concentrations of intracellular solutes within the recently characterized extremely halophilic flagellate protozoa $[14,15]$. We do, however, have a quite complete picture of the distribution of organic solutes in most other groups of halophilic microorganisms. Glycerol and other polyols are widely used for osmotic adaptation in halophilic eukaryotic algae and fungi, but only seldom in the the prokaryotes, the finding of mannitol in Pseudomonas putida [51] being a notable exception. The occurrence of certain other solutes in halophilic and halotolerant prokaryotes is also often correlated with their position in the phylogenetic tree of life.

Within the domain Archaea we find a few solutes not yet detected elsewhere within the tree [49]. Halophilic methanogens such as the Methanohalophilus species contain, in addition to glycine betaine found widespread in nature, $\beta$ amino acids and derivatives that are rarely found in other groups: $\beta$-glutamine, $\beta$-glutamate, and $\mathrm{N} \varepsilon$-acetyl- $\beta$-lysine $([49,52]$; for a report on the occurrence of $\beta$-glutamate in the domain Bacteria see [53]). Sulfotrehalose has thus far been found only in a few alkaliphilic members of the Halobacteriaceae; it is accumulated in substantial concentrations (up to $1 \mathrm{M}$ ) in addition to $\mathrm{KCl}$ which serves as the main osmotic solute like in their neutrophilic relatives [54].

In the kingdom Bacteria the largest diversity of organic solutes is detected. Some compounds appear to be used by a wide range of organisms. Glycine betaine is readily used as osmotic solute by many different types [55], but 


\section{Glycerol

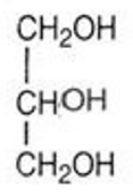

Glycine betaine<smiles>C[N+](C)(C)CC=O</smiles>

\section{L- $\alpha$-Glutamate}<smiles>[NH3+]C(CCC(=O)O)C(=O)[O-]</smiles>

\section{$\beta$-Glutamine}<smiles>NC(=O)CC(N)CC(=O)O</smiles>

Ne-Acetyl- $\beta$-Lysine<smiles>CC(=O)NCCC[C@H](N)CC(=O)[O-]</smiles>

Ectoine<smiles>CC1=NCC[C@H](C(=O)[O-])N1</smiles>

Trehalose

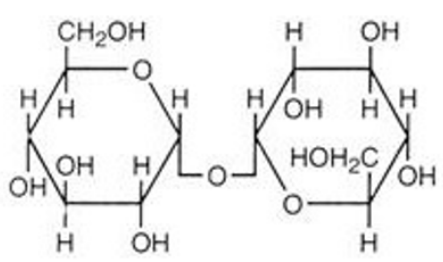

\section{$\beta$-Glutamate}<smiles>CC(=O)OCC(=O)O</smiles>

\section{L-Proline}<smiles>O=C([O-])C1CCCN1</smiles>

\section{Sulfotrehalose}

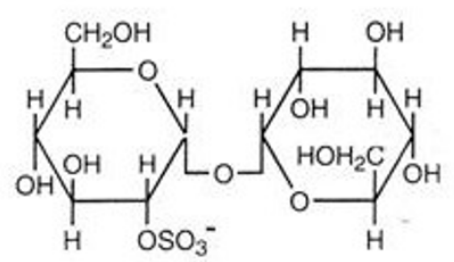

Figure 4

A selection of organic osmotic solutes found in halophilic and halotolerant prokaryotic and eukaryotic microorganisms. 


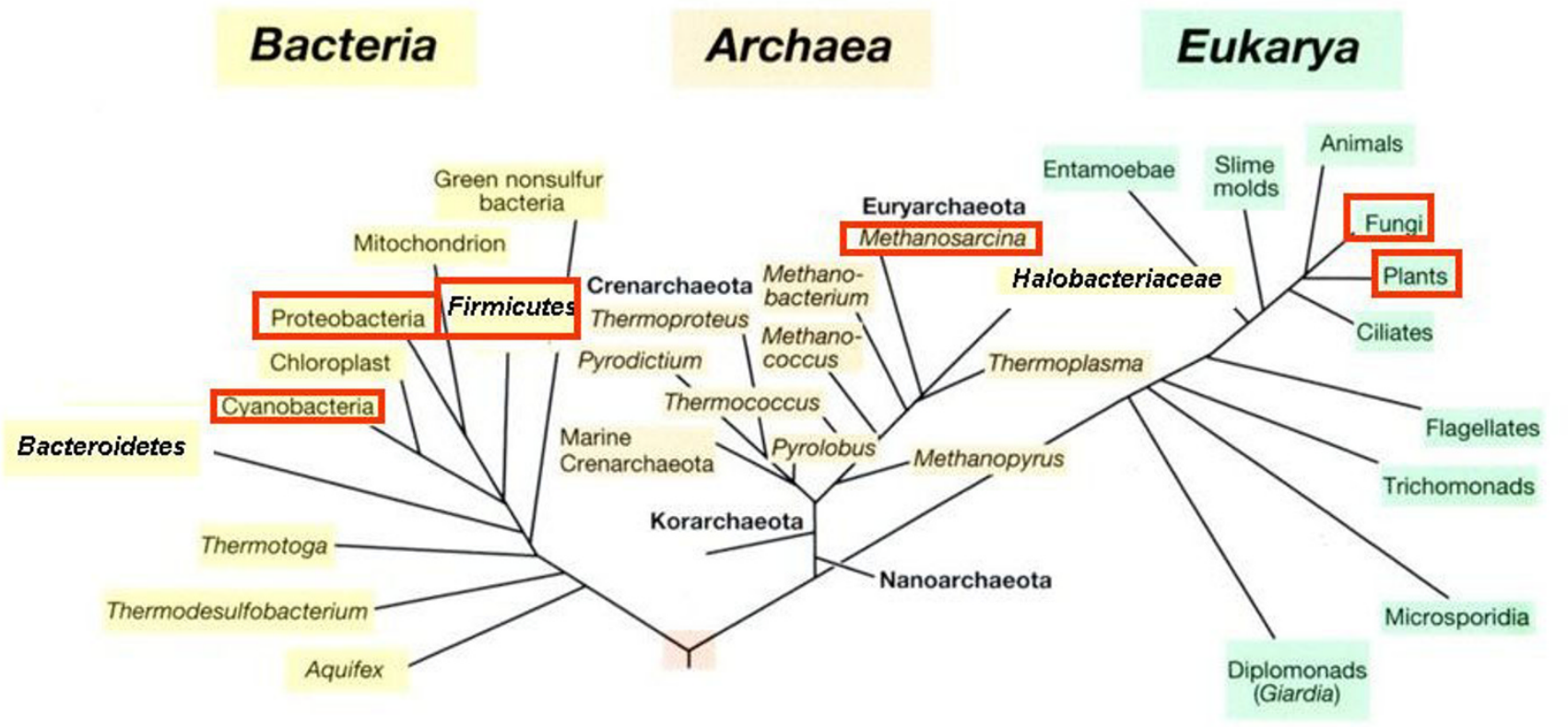

Figure 5

Distribution within the phylogenetic tree of microorganisms accumulating organic solutes to provide osmotic balance. Groups marked with red boxes contain at least some halophilic representatives in which de novo synthesis and/or accumulation of organic solutes has been demonstrated. The group of the Firmicutes contains both halophilic aerobes that accumulate organic solutes and anaerobic fermentative microorganisms (the order Halanaerobiales) that use $\mathrm{KCl}$.

only when it can be taken up from the medium. Relatively few prokaryotes are capable of de novo synthesis of the compound. Notably these are different types of phototrophs: halophilic cyanobacteria as well as anoxygenic phototrophs such as Halorhodospira spp. Occurrence of glycine betaine biosynthesis in the heterotrophic Actinopolyspora halophila (Actinobacteria) has been established long ago. In recent years the list of non-phototrophic prokaryotes capable of de novo production of glycine betaine as regulated by the extracellular salt concentration has grown. The methanogenic archaeon Methanohalophilus portucalensis synthesizes glycine betaine by reductive methylation of glycine that is generated from serine [50,56-59]. In contrast, the far less halotolerant Methanosarcina mazei does not produce glycine betaine, but accumulates the compound from the medium when exposed to salt stress. Recently evidence was obtained for de novo biosynthesis of glycine betaine also in the haloalkaliphilic chemoautotrophic sulfur-oxidizing Proteobacteria Thioalkalibacter and Thioalkalivibrio [60,61], but no information is as yet available about the biosynthetic pathway used and its regulation.

Far more abundant than glycine betaine as compatible solute in the domain Bacteria are the cyclic amino acid derivatives ectoine and hydroxyectoine, originally discovered in anoxygenic phototrophs of the Ectothiorhodospira Halospira group [48]. Ectoine is now known to be synthesized by many aerobic heterotrophic bacteria $[5,49]$. Ectoine was also recently identified as a major osmotic solute in halophilic methanotrophs and methylotrophs $[62,63]$.

The list of organic compatible solutes that have been identified is long, and Fig. 4 gives a representative selection only. Some compounds are widespread along the phylogenetic tree, while others appear to be limited to selected groups. For example, glucosylglycerol is almost exclusively found in moderately halophilic or highly halotolerant cyanobacteria, but has been detected in some pseudomonads as well [64,65]; $\mathrm{N} \varepsilon$-acetyl- $\alpha$-lysine and $\mathrm{N} \delta$-acetylornithine have thus far been detected only in aerobic members of the Firmicutes. Another compound of interest is proline, found especially in the Firmicutes $[66,67]$, but also present in halophilic/halotolerant diatoms [68]. A special biosynthetic pathway for the production of proline for osmotic purposes has been detected in Bacillus subtilis [69]. 
Use of organic osmotic solutes, whose intracellular concentrations can be regulated in accordance with the external salt concentration, provides microorganisms with a large degree of flexibility and the possibility to adapt to a wide range of salt concentrations $[5,48]$. However, energetically the production of massive amounts of such solutes can be costly. In addition, energy is still needed to prevent salts from reaching the cytoplasm. The high energy cost involved is especially relevant for microorganisms that obtain small amounts of energy from the dissimilatory processes they perform. A calorimetric study with Halomonas elongata, a bacterium that produces ectoine as its main compatible solute, shows that the organism has optimized its metabolism to minimize the energetic cost of osmotic adaptation [70]. It is well possible that the upper salinity at which different metabolic types of prokaryotes are found in nature depends to a large extent on the balance between the amount of energy that is available to the cells and the cost of production of organic solutes needed to provide osmotic balance [41].

\section{The case of Salinibacter, a member of the Bacteria with archaeal characteristics}

Until recently it was generally accepted that halophilic members of the bacterial domain use organic solutes for osmotic balance. The sole exception known was that of the Halanaerobiales, a group of fermentative halophiles phylogenetically affiliated with the low $\mathrm{G}+\mathrm{C}$ branch of the Firmicutes. It was also clear why the 'high-salt-in strategy' would be the preferred or possibly the only feasible mode of haloadaptation in this group: only very little energy is obtained in the fermentation pathways that provide ATP to these organisms, and accordingly the production of massive amounts of organic compatible solutes would leave insufficient energy for other cellular functions [41].

The discovery of Salinibacter and the analysis of its properties (Table 1) now require a change in our views. Salinibacter ruber is a red extreme halophile, phylogenetically belonging to the Bacteroidetes branch of the Bacteria, and it coexists with Archaea of the family Halobacteriaceae in $\mathrm{NaCl}$-saturated saltern crystallizer ponds and in other hypersaline environments at or approaching halite saturation. Its existence was first recognized in the late 1990s based on the molecular characterization of the microbial community in Spanish saltern crystallizer ponds [71]. The isolation of the organism soon followed [72-74].

The affiliation of Salinibacter with the Bacteria appears not only from the sequence of its $16 \mathrm{~S}$ rRNA gene, but also from the nature of the lipids in its membrane - bacterial lipids, in part of an unusual type, but with conventional fatty acids rather than the archaeal phytanyl-based hydrophobic chains [75]. The sensitivity of Salinibacter to antibiotics points to the presence of peptidoglycan in its cell wall. It was therefore expected that, like all other known halophilic and halotolerant aerobic Bacteria, Salinibacter would contain an organic solute or a cocktail of such solutes. However, no significant concentrations of organic solutes were detected. Instead, the cells contain molar concentrations of $\mathrm{KCl}$ [76], and its proteome is highly acidic, nearly as much so as the proteome of Halobacterium [77]. Analysis of the genome of S. ruber showed many additional common properties with the extremely halophilic Archaea. Extensive gene exchange may have occurred between Salinibacter and the Halobacteriaceae, which share the same environment and have been subject to the same environmental stress factors throughout their evolutionary history [77].

\section{Final comments}

Based on all the new information that has become available in the past two decades we can now reevaluate the four 'postulates' presented by Trüper at the Alicante 1989 halophile symposium [1]:

(1) "All eubacteria that gain energy from photosynthesis or oxygen-respiration and are capable of haloadaptation, are able to accumulate and/or produce compatible solutes."

For the Bacteria that lead an oxygenic or anoxygenic phototrophic life this statement is still true. However, the discovery of Salinibacter ruber, phylogenetically affiliated

Table I: A comparison of the properties of

\begin{tabular}{lll}
\hline & Salinibacter & Halobacteriaceae \\
\hline Salt requirement & $>150 \mathrm{~g} / \mathrm{l}$ & $>150 \mathrm{~g} / \mathrm{l}$ in most species \\
Salt optimum & $\mathrm{I} 50-300 \mathrm{~g} / \mathrm{l}$ & $200-250 \mathrm{~g} / \mathrm{l}$ in most species \\
$\mathrm{G}+\mathrm{C} \%$ in DNA & 66.2 & $59-7 \mathrm{I} ; 46.9$ in Haloquadratum walsbyi \\
Osmotic solute & $\mathrm{KCl}$ & $\mathrm{KCl}$ \\
Enzymes & Salt-requiring and salt-tolerant & $\mathrm{Mostly}$ salt-requiring \\
Lipids & Bacterial, including unusual sulfonolipids & Archaeal \\
Carotenoid pigments & C-40 substituted carotenoid ('salinixanthin') & C-50 bacterioruberins \\
Retinal pigments & Bacteriorhodopsin ('xanthorhodopsin'), halorhodopsin (not yet & Bacteriorhodopsin, halorhodopsin, sensory rhodopsins \\
& proven to be functional), sensory rhodopsins & (in many but not in all species)
\end{tabular}


with the Bacteroidetes but physiologically behaving like a member of the Halobacteriaceae, shows that the 'high-saltin strategy' of osmotic adaptation, based on the accumulation of $\mathrm{KCl}$ and the adaptation of the entire intracellular enzymatic machinery to the presence of high salt concentrations, also occurs in some oxygen-respiring members of the domain Bacteria.

(2) "Archaeobacteria and anaerobic fermenting eubacteria are incapable of synthesizing organic compatible solutes."

No cases of anaerobic fermenting Bacteria that produce organic osmotic solutes have yet been documented. However, compatible solutes have been detected in several groups of halophilic Archaea. Methanogenic Archaea (also the non-halophilic ones) contain high concentrations of $\mathrm{KCl}$, but in the halophilic types such as Methanohalophilus spp. different organic solutes are known to occur: glycine betaine, and $\beta$-amino acids and derivatives. The intracellular concentrations of at least some of these compounds are regulated in accordance with the salinity of the environment. Another case of organic solutes discovered in Archaea is that of sulfotrehalose which, together with $\mathrm{KCl}$, appears to play a role in the osmotic adaptation of some haloalkaliphilic members of the Halobacteriaceae.

(3) "Most eubacteria that can grow in non-complex media are capable of ectoine biosynthesis."

Ectoine indeed appears to be the nearly universal organic compatible solutes in the Bacteria, and its biosynthesis has been documented in a wide variety of halophilic and halotolerant species, and notably in species with simple growth demands.

(4) "Extreme halophily in non-fermenting eubacteria is usually accompanied by glycine betaine biosynthesis. The complete de novo synthesis of betaine from carbon dioxide or simple organic carbon compounds has only been proven for cyanobacteria, Ectothiorhodospira species and Actinopolyspora halophila."

The truly halophilic species within the genus Ectothiorhodospira have since been reclassified in the newly created genus Halorhodospira. The finding of complete de novo biosynthesis of glycine betaine in the methanogenic archaeon Methanohalophilus portucalensis and in haloalkaliphilic bacterial chemolithotrophs shows that production of this simple solute may be more widespread than previously assumed.

Summarizing all these new data, it becomes ever more difficult to formulate general trends to describe the relations between halophily, taxonomy, phylogeny and nomenclature. The halophilic microbial world is tremendously diverse, and novel types of halophiles are being discovered at an ever-increasing rate. The case of Salinibacter ruber shows that some of these newly described organisms may necessitate us to revise our concepts on how the different physiological and phylogenetic groups of microorganisms have solved the problem how to cope with high salt concentrations in their environment. Hypersaline environments are extremely diverse, and so are the microorganisms that inhabit them.

\section{Acknowledgements}

I thank the anonymous reviewers for their helpful comments. My studies on diversity and physiology of halophilic microorganisms are currently supported by the Israel Science Foundation (grant no. 617/07).

\section{References}

I. Trüper HG, Severin J, Wolhfarth A, Müller E, Galinksi EA: Halophily, taxonomy, phylogeny and nomenclature. In General and Applied Aspects of Halophilism Edited by: Rodriguez-Valera F. New York: Plenum Press; 1991:3-7.

2. Kushner DJ: Life in high salt and solute concentrations. In Microbial Life in Extreme Environments Edited by: Kushner DJ. London: Academic Press; 1978:317-368.

3. Oren A: Halophilic Microorganisms and their Environments. Dordrecht: Kluwer Scientific Publishers; 2002.

4. Oren A: Life at high salt concentrations. In The Prokaryotes. A Handbook on the Biology of Bacteria: Ecophysiology and Biochemistry Volume 2. Edited by: Dworkin M, Falkow S, Rosenberg E, Schleifer K-H, Stackebrandt E. New York: Springer; 2006:263-282.

5. Ventosa A, Nieto JJ, Oren A: Biology of aerobic moderately halophilic bacteria. Microbiol Mol Biol Rev 1998, 62:504-544.

6. Oren A: Diversity of halophilic microorganisms: environments, phylogeny, physiology, and applications. J Ind Microbiol Biotechnol 2002, 28:56-63.

7. Oren A: A hundred years of Dunaliella research - 1905-2005. Saline Systems 2005, I:2.

8. Zalar P, de Hoog S, Gunde-Cimerman N: Trimmatostroma salinum, a new species from hypersaline water. Stud Mycol 1999, 43:57-62.

9. Gunde-Cimerman N, Zalar P, de Hoog S, Plemenitaš A: Hypersaline waters in salterns - natural ecological niches for halophilic black yeasts. FEMS Microbiol Ecol 2000, 32:235-240.

10. Elazari-Volcani B: dimastigamoeba in the bed of the Dead Sea. Nature 1943, 152:275-277.

II. Elazari-Volcani B: A ciliate from the Dead Sea. Nature 1944, 154:335-336.

12. Hauer G, Rogerson A: Heterotrophic protozoa from hypersaline environments. In Adaptation to Life at High Salt Concentrations in Archaea, Bacteria, and Eukarya Edited by: Gunde-Cimerman N, Oren A, Plemenitaš A. Dordrecht: Springer; 2005:522-539.

13. Cho BC: Heterotrophic flagellates in hypersaline waters. In Adaptation to Life at High Salt Concentrations in Archaea, Bacteria, and Eukarya Edited by: Gunde-Cimerman N, Oren A, Plemenitaš A. Dordrecht: Springer; 2005:543-549.

14. Park JS, Simpson AGB, Lee WJ, Cho BC: Ultrastructure and phylogenetic placement within Heterolobosea of the previously unclassified, extremely halophilic heterotrophic flagellate Pleurostomum flabellatum (Ruinen 1938). Protist 2007, 158:397-4I3.

15. Park JS, Cho BC, Simpson AGB: Halocafetaria seosinensis gen. et sp. nov. (Bicosoecida), a halophilic bacterivorous nanoflagellate isolated from a solar saltern. Extremophiles 2006, 10:493-504.

16. Oren A: The order Halobacteriales. In The Prokaryotes. A Handbook on the Biology of Bacteria Volume 3. 3rd edition. Edited by: Dworkin M, Falkow S, Rosenberg E, Schleifer K-H, Stackebrandt E. New York: Springer; 2006:1 I3-164. 
17. Arahal DR, Ventosa A: The family Halomonadaceae. In The Prokaryotes. A Handbook on the Biology of Bacteria Volume 6. 3rd edition. Edited by: Dworkin M, Falkow S, Rosenberg E, Schleifer K-H, Stackebrandt E. New York: Springer; 2006:8I I-835.

18. Oren A: The order Haloanaerobiales. In The Prokaryotes. A Handbook on the Biology of Bacteria Volume 4. 3rd edition. Edited by: Dworkin M, Falkow S, Rosenberg E, Schleifer K-H, Stackebrandt E. New York: Springer; 2006:804-817.

19. Gibbons NE: Family V. Halobacteriaeae. In Bergey's Manual of Determinative Bacteriology Edited by: Buchanan RE, Gibbons NE. Baltimore: Willams \& Wilkins; 1974:269-273.

20. Grant WD, Larsen H: Extremely halophilic archaeobacteria, order Halobacteriales ord. nov. In Bergey's Manual of Systematic Bacteriology Volume 3. Edited by: Staley JT, Bryant MP, Pfennig N, Holt JG. Baltimore: Williams \& Wilkins; 1989:2216-2233.

21. Grant WD, Kamekura M, McGenity TJ, Ventosa A: Class III Halobacteria class. nov. In Bergey's Manual of Systematic Bacteriology Volume I. 2nd edition. Edited by: Boone DR, Castenholz RW, Garrity GM. New York: Springer; 2001:294-334.

22. Elshahed MS, Najar FZ, Roe BA, Oren A, Dewers TA, Krumholz LR: Survey of archaeal diversity reveals abundance of halophilic Archaea in a low-salt, sulfide- and sulfur-rich spring. Appl Environ Microbiol 2004, 70:2230-2239.

23. Elshahed MS, Savage KN, Oren A, Gutierrez MC, Ventosa A, Krumholz LR: Haloferax sulfurifontis sp. nov., a halophilic archaeon isolated from a sulfide and sulfur-rich spring. Int J Syst Evol Microbiol 2004, 54:2275-2279.

24. Savage KN, Krumholz LR, Oren A, Elshahed MS: Haladaptatus paucihalophilus gen. nov., sp. nov., a halophilic archaeon isolated from a low-salt, high-sulfide spring. Int J Syst Evol Microbiol 2007, 57:19-24.

25. Savage KN, Krumholz LR, Oren A, Elshahed MS: Halosarcina pallida gen. nov., sp. nov., a halophilic archaeon isolated from a lowsalt, sulfide-rich spring. Int I Syst Evol Microbiol 2008 in press.

26. Torreblanca M, Rodriguez-Valera R, Juez G, Ventosa A, Kamekura M, Kates M: Classification of non-alkaliphilic halobacteria based on numerical taxonomy and polar lipid composition, and description of Haloarcula gen. nov. and Haloferax gen. nov. System Appl Microbiol 1986, 8:89-99.

27. Fukushima T, Usami R, Kamekura M: A traditional Japanese-style salt field is a niche for haloarchaeal strains that can survive in 0.5\% salt solution. Saline Systems 2007, 3:2.

28. Purdy KJ, Cresswell-Maynard TD, Nedwell DB, McGenity TJ, Grant WD, Timmis KN, Embley TM: Isolation of haloarchaea that grow at low salinities. Environ Microbiol 2004, 6:591-595.

29. Papke RT, Zhaxybayeva O, Feil EJ, Sommerfeld K, Muise D, Doolittle WF: Searching for species in haloarchaea. Proc Natl Acad Sci USA 2007, I 04: | 4092-I4097.

30. Vreeland RH, Litchfield CD, Martin EL, Eliot E: Halomonas elongata, a new genus and species of extremely salt-tolerant bacteria. Int ] Syst Bacteriol 1980, 30:485-495.

31. Franzmann PD, Wehmeyer U, Stackebrandt E: Halomonadaceae fam. nov., a new family of the class Proteobacteria to accommodate the genera Halomonas ad Deleya. Syst Appl Microbiol 1988, I I:16-19.

32. Mata JA, Martinez-Canovas J, Quesada E, Bejar V: A detailed phenotypic characterization of the type strain of Halomonas species. Syst Appl Microbiol 2002, 25:360-375.

33. Arahal DR, Vreeland RH, Litchfield CD, Mormile MR, Tindall BJ, Oren $A$, Bejar V, Quesada E, Ventosa A: Recommended minimal standards for describing new taxa of the family Halomonadaceae. Int J Syst Evol Microbiol 2007, 57:2436-2446.

34. Ntougias S, Zervakis GI, Fasseas C: Halotalea alkalilenta gen. nov., sp. nov., a novel osmotolerant and alkalitolerant bacterium from alkaline olive mill wastes, and emended description of the family Halomonadaceae Franzmann et al. emend. Dobson and Franzmann 1996. Int J Syst Evol Microbiol 1989, 57:1975-1983

35. Ben Ali Gam Z, Abdelkafi S, Casalot L, Tholozan JL, Oueslati R, Labat M: Modicisalibacter tunisiensis gen. nov., sp. nov., an aerobic, moderately halophilic bacterium isolated from an oilfieldwater injection sample, and emended description of the family Halomonadaceae Franzmann et al. 1989, emend. Dobson and Franzmann 1996 emend. Ntougias et al. 2007. Int J Syst Evol Microbiol 2007, 57:2307-23।3.
36. Switzer Blum J, Stolz JF, Oren A, Oremland RS: Selenihalanaerobacter shriftii gen. nov., sp. nov., a halophilic anaerobe from Dead Sea sediments that respires selenate. Arch Microbiol 200I, I 75:208-219.

37. Cayol J-L, Ollivier B, Patel BKC, Prensier G, Guezennec J, Garcia J-L: Isolation and characterization of Halothermothrix orenii gen. nov., sp. nov., a halophilic, thermophilic, fermentative, strictly anaerobic bacterium. Int J Syst Bacteriol 1994, 44:534-540.

38. Brown AD: Microbial water stress. Bacteriol Rev 1976, 40:803-846.

39. Brown AD: Microbial Water Stress Physiology. Principles and Perspectives. Chichester: John Wiley \& Sons; 1990.

40. Lanyi JK: Salt dependent properties of proteins from extremely halophilic bacteria. Bacteriol Rev 1974, 38:272-290.

4I. Oren A: Bioenergetic aspects of halophilism. Microbiol Mol Biol Rev 1999, 63:334-348.

42. Ng WV, Kennedy SP, Mahairas GG, Berquist B, Pan M, Shukla HD, Lasky SR, Baliga NS, Thorsson V, Sbrogna J, Swartzell S, Weir D, Hall J, Dahl TA, Welti R, Goo YA, Leithausen B, Keller K, Cruz R, Danson M], Hough DW, Maddocks DG, Jablonski PE, Krebs MP, Angevine GM, Dale H, Isenbarger TA, Peck RF, Pohlschröder M, Spudich JL, Jung K-H, Alam M, Freitas T, Hou S, Daniels CJ, Dennis PP, Omer AD, Ebhardt H, Lowe TM, Liang P, Riley M, Hood L, DasSarma S: Genome sequence of Halobacterium species NRC-I. Proc Nat Acad Sci USA 2000, 97:12176-12181

43. Kennedy SP, Ng WV, Salzberg SL, Hood L, DasSarma S: Understanding the adaptation of Halobacterium species NRC-I to its extreme environment through computational analysis of its genome sequence. Genome Res 2001, I I: I641-1650.

44. Baliga NS, Bonneau R, Facciotti MT, Pan M, Glusman G, Deutsch EW, Shannon P, Chiu Y, Sting Weng R, Richie Gan R, Hung P, Date SV, Marcotte E, Hood L, Ng WV: Genome sequence of Haloarcula marismortui: a halophilic archaeon from the Dead Sea. Genome Res 2004, 14:2221-2234.

45. Falb M, Pfeiffer F, Palm P, Rodewald K, Hickmann V, Tittor J, Oesterhelt $D$ : Living with two extremes: conclusions from the genome sequence of Natronomonas pharaonis. Genome Res 2005, I5:1336-1343.

46. Bolhuis H, Palm P, Wende A, Falb M, Rampp M, Rodriguez-Valera F, Pfeiffer $F$, Oesterhelt $D$ : The genome of the square archaeon "Haloquadratum walsbyi": life at the limits of water activity. BMC Genomics 2006, 7:169.

47. Oren A: Intracellular salt concentrations of the anaerobic halophilic eubacteria Haloanaerobium praevalens and Halobacteroides halobius. Can I Microbiol 1986, 32:4-9.

48. Galinski EA: Osmoadaptation in bacteria. Adv Microb Physiol 1986, 37:273-328.

49. Roberts MF: Organic compatible solutes of halotolerant and halophilic microorganisms. Saline Syst 2005, I:5.

50. Roberts MF: Characterization of organic compatible solutes of halotolerant and halophilic microorganisms. In Methods in Microbiology, Extremophiles Volume 35. Edited by: Rainey FA, Oren A. Amsterdam: Elsevier-Academic Press; 2006:615-647.

51. Kets EP, Galinski EA, de Wit M, de Bont JAM, Heipieper HJ: Mannitol, a novel bacterial compatible solute in Pseudomonas putida S I 2. I Bacteriol 1996, I 78:6665-6670.

52. Lai M, Sowers KR, Robertson DE, Roberts MF, Gunsalus RP: Distribution of compatible solutes in the halophilic methanogenic archaebacteria. J Bacteriol I99|, I 73:5352-5358.

53. Galinski EA, Trüper HG: Microbial behaviour in salt-stressed ecosystems. FEMS Microbiol Rev 1994, I 5:95-108.

54. Desmarais D, Jablonski PE, Fedarko NS, Roberts MF: 2-Sulfotrehalose, a novel osmolyte in haloalkaliphilic archaea. J Bacteriol 1997, I79:3146-3153.

55. Imhoff JF, Rodriguez-Valera F: Betaine is the main compatible solute of halophilic eubacteria. J Bacteriol 1984, 160:478-479.

56. Roberts MF, Lai MC, Gunsalus RF: Biosynthetic pathway of the osmolytes $\mathbf{N} \varepsilon$-acetyl- $\beta$-lysine, $\beta$-glutamine, and betaine in Methanohalophilus strain FDFI suggested by nuclear magnetic resonance analyses. J Bacteriol 1992, I 74:6688-6693.

57. Robertson DE, Lai M-C, Gunsalus RF, Roberts MF: Composition, variation, and dynamics of major osmotic solutes in Methanohalophilus strain FDFI. Appl Environ Microbiol 1992, 58:2438-2443.

58. Lai M-C, Yang M-R, Chuang M-J: Regulatory factors associated with synthesis of the osmolyte glycine betaine in the halo- 
philic methanoarchaeon Methanohalophilus portocalensis. Appl Environ Microbiol 1999, 63:828-833.

59. Lai M-C, Wang C-C, Chuang M-J, Wu Y-C, Lee Y-C: Effects of substrate and potassium on the betaine-synthesizing enzyme glycine sarcosine dimethylglycine $\mathbf{N}$-methyltransferase from a halophilic methanoarchaeon Methanohalophilus portucalensis. Res Microbiol 2006, I 57:948-955.

60. Banciu H, Sorokin DY, Galinski EA, Muyzer G, Kleerebezem R, Kuenen JG: Thialkalivibrio halophilus sp. nov., a novel obligately chemolithoautotrophic, facultatively alkaliphilic, and extremely salt-tolerant, sulfur-oxidizing bacterium from a hypersaline alkaline lake. Extremophiles 2004, 8:325-334.

6I. Banciu H, Sorokin DY, Rijpstra WIC, Sinninghe Damsté JS, Galinski EA, Takaichi S, Muyzer G, Kuenen JG: Fatty acid, compatible solute and pigment composition of obligately chemolithoautotrophic alkaliphilic sulfur-oxidizing bacteria from soda lakes. FEMS Microbiol Lett 2005, 243:181-187.

62. Khmelenina VN, Kalyuzhnaya MG, Sakharovsky VG, Suzina NE, Trotsenko YA, Gottschalk G: Osmoadaptation in halophilic and alkaliphilic methanotrophs. Arch Microbiol 1999, 172:32 I-329.

63. Trotsenko YA, Khmelenina VN: Biology of extremophilic and extremotolerant methanotrophs. Arch Microbiol 2002, 177:123-131.

64. Pocard J-A, Tombras Smith L, Smith GM, Le Rudulier D: A prominent role for glucosylglycerol in the adaptation of Pseudomonas mendocina SKB70 to osmotic stress. J Bacteriol I994, I 76:6877-6884.

65. Mikkat S, Galinski EA, Berg G, Minkwitz A, Schoor A: Salt adaptation in pseudomonads: characterization of glucosylglycerolsynthesizing isolates from brackish coastal waters and the rhizosphere. System Appl Microbiol 2000, 23( I):3 I-40.

66. Kuhlmann $\mathrm{AU}$, Bremer $\mathrm{E}$ : Osmotically regulated synthesis of the compatible solute ectoine in Bacillus pasteurii and related Bacillus spp. Appl Environ Microbiol 2002, 68:772-783.

67. Saum SH, Müller V: Salinity-dependent switching of osmolyte strategies in a moderately halophilic bacterium: glutamate induces proline biosynthesis in Halobacillus halophilus. J Bacteriol 2007, 189:6968-6975.

68. Schobert B: Influence of water stress on metabolism of diatoms. 2. Proline accumulation under different conditions of stress and light. Zeitschr Pflanzenphysiol I 977, 85:45I-46I.

69. Belitsky BR, Brill J, Bremer E, Sonenshein AL: Multiple genes for the last step of proline biosynthesis in Bacillus subtilis. J Bacteriol 200I, 183:4389-4392.

70. Maskov T, Babel W: Calorimetrically obtained information about the efficiency of ectoine synthesis from glucose in Halomonas elongata. Biochim Biophys Acta 200I, I 527:4-10.

71. Antón J, Rosselló-Mora R, Rodríguez-Valera R, Amann R: Extremely halophilic bacteria in crystallizer ponds from solar salterns. Appl Environ Microbiol 2000, 66:3052-3057.

72. Antón J, Oren A, Benlloch S, Rodríguez-Valera F, Amann R, RossellóMora R: Salinibacter ruber gen. nov., sp. nov., a novel extreme halophilic member of the Bacteria from saltern crystallizer ponds. Int J Syst Evol Microbiol 2002, 52:485-49I.

73. Oren A, Rodríguez-Valera F, Antón J, Benlloch S, Rosselló-Mora R, Amann R, Coleman J, Russell NJ: Red, extremely halophilic, but not archaeal: the physiology and ecology of Salinibacter ruber, a bacterium isolated from saltern crystallizer ponds. In Halophilic Microorganisms Edited by: Ventosa A. Berlin: Springer-Verlag: 2004:63-76.

74. Oren A: The genera Rhodothermus, Thermonema, Hymenobacter and Salinibacter. In The Prokaryotes. A Handbook on the Biology of Bacteria Volume 7. 3rd edition. Edited by: Dworkin M, Falkow S, Rosenberg E, Schleifer K-H, Stackebrandt E. New York: Springer; 2006:7I 2-740.

75. Corcelli A, Lattanzio VMT, Mascolo G, Babudri F, Oren A, Kates M: Novel sulfonolipid in the extremely halophilic bacterium Salinibacter ruber. Appl Environ Microbiol 2004, 70:6678-6685.

76. Oren A, Heldal M, Norland S, Galinski EA: Intracellular ion and organic solute concentrations of the extremely halophilic bacterium Salinibacter ruber. Extremophiles 2002, 6:491-498.

77. Mongodin MEF, Nelson KE, Duagherty S, DeBoy RT, Wister J, Khouri H, Weidman J, Balsh DA, Papke RT, Sanchez Perez G, Sharma AK, Nesbo CL, MacLeod D, Bapteste E, Doolittle WF, Charlebois RL, Legault B, Rodríguez-Valera F: The genome of Salinibacter ruber: convergence and gene exchange among hyperhalophilic bacteria and archaea. Proc Natl Acad Sci USA 2005, I02:18147-|8|52. 78. Madigan MT, Martinko JM: Brock Biology of Microorganisms. I I th edition. Upper Saddle River: Pearson/Prentice Hall .
Publish with Biomed Central and every scientist can read your work free of charge

"BioMed Central will be the most significant development for disseminating the results of biomedical research in our lifetime. "

Sir Paul Nurse, Cancer Research UK

Your research papers will be:

- available free of charge to the entire biomedical community

- peer reviewed and published immediately upon acceptance

- cited in PubMed and archived on PubMed Central

- yours - you keep the copyright 